\title{
Biometric properties of onion seedlings relevant to the development of onion seedling transplanter
}

\author{
Ashutosh Pandirwar ${ }^{1 *}$, Adarsh Kumar ${ }^{1}$, Indra Mani ${ }^{1}$ and Sabina Islam ${ }^{2}$ \\ ${ }^{1}$ Division of Agricultural Engineering, IARI, New Delhi-110012, INDIA \\ ${ }^{2}$ Division of Vegetable Science, IARI, New Delhi-110012, INDIA \\ *Corresponding author. E-mail: ashu4725@gmail.com \\ Received: November 13, 2014; Revised received: August 5, 2015; Accepted: September 30, 2015
}

\begin{abstract}
A study was conducted to investigate biometric properties of seedlings of three common varieties of onion viz. Pusa Red, Set-126 and Pusa Ridhi $(50,60,70$ days old). The parameters determined were weight of seedling without and with de-topping, bulb diameter, stem diameter, height, moisture content, compressive strength and coefficient of static friction. The weight of seedlings without de-topping ranged from 0.53 to $3.05 \mathrm{~g}$ while with de-topping ranged from 0.47 to $1.68 \mathrm{~g}$ for all the three cultivars. The bulb and stem diameter for all varieties ranged from 3.13 to $5.76 \mathrm{~g}$ for bulb and 2.44 to $4.33 \mathrm{~g}$ for stem whereas height varied from $14.48 \mathrm{~cm}$ to $34.65 \mathrm{~cm}$, among all Pusa red was taller than Set-126 and Pusa Ridhi. The moisture content at different age and for all cultivars ranged from 84.89 to $91.63 \%(\mathrm{wb})$. The average coefficient of static friction for mild steel (MS), aluminum and galvanized iron (GI) varied from 0.63 to 0.79 . The compressive strength of bulb and stem of seedlings were 9.76 to $19.54 \mathrm{~N}$ for bulb and 4.08 to $8.17 \mathrm{~N}$ for stem respectively for 50 to 70 days seedlings. This information was not available but is critical in designing and selection of different components of onion seedling transplanter.
\end{abstract}

Keywords: Coefficient of static friction, Compressive strength, Diameter, Height, Onion, Weight

\section{INTRODUCTION}

Onion (Allium cepa L.) is the most important vegetable crop grown and consumed all over the country. It is used as salad and cooked in many ways in fried, curries, baked, boiled and used to prepare pickles, soups etc. These are also dehydrated in the form of powder and flakes for use as spice. Onion bulbs are rich in minerals like calcium (180 mg / $100 \mathrm{~g})$ and phosphorus (50 mg / $100 \mathrm{~g}$ ). Many medicinal uses are reported for bulbs and is commonly used as diuretic and applied traditionally on wounds and boils (Sampath et al., 2010). India is the second largest producer of onion in the world, next to China and ranks third in export, after Netherlands and Spain. Onion is exported to many countries (Malaysia, Qatar, Kuwait, Singapore, Pakistan, United Arab Emirates, Sri Lanka, Bangladesh, Oman, Nepal) (APEDA, 2015). During 2013-2014, a total 19.3 million tons of bulbs were produced from an area of 1.22 million hectares in India (NHRDF, 2014). Maharashtra is the leading onion producing state in India followed by Karnataka and Madhya Pradesh. The crop is also grown extensively in Orissa, Andhra Pradesh, Gujarat, Uttar Pradesh, Tamil Nadu, Rajasthan and Bihar. In India, onion is grown in kharif, late kharif and rabi seasons. Traditionally, onion nurseries are prepared and then transplanting is done manually. Manual transplanting on a large commercial scale is labor intensive and expensive. Also, onion plants are delicate and perishable which leads to higher seedling mortality. Rising labor costs and uncertainty of labor availability has forced some growers to look at the option of mechanical transplanting. In designing a machine for transplanting, harvesting of these seedlings, physical properties such as weight, bulb diameter, shape factor, height, compressive strength, coefficient of friction on different surfaces are of paramount importance. In recent years, many researchers have reported physical and mechanical properties of onion crop relevant to different mechanical operations such as de-topping and harvesting. But there are very few studies on the physical and mechanical properties of onion seedlings for mechanical transplanting. The study of engineering properties of onion seedlings before design of machine is important as they are prone to mechanical damage as compared to other vegetable seedlings. Vijaya and Srivastava (2006) determined physical and mechanical properties of onion crop such as polar and equatorial diameters, shape and shape factor, diameter at neck, length of leaves, number of leaves, weight of onion bulb with leaves, moisture content of onion bulb and leaves, and bulk density which are relevant to mechanical de-topping. Bahnasawy et al. (2004) studied some physical and mechanical properties of some Egyptian onion cultivars which are important to understand the behavior of the product during the post har- 
vesting operations such as harvesting, transporting, sorting, grading, packaging and storage processes. Khura et al. (2010) studied engineering properties of onion crop relevant to design of onion digger. The information was used to design different components of an onion digger. The physical characteristics of seeds and fertilizers like size, shape, coefficient of friction and aerodynamic resistance of particles strongly influence their movements both in machines as well as in the air. It is therefore important to study these properties when constructing such machineries (Csizmazia and Polyak, 1994). Some studies have also been done on engineering properties of garlic which are closer to properties of onion. Manjunatha et al. (2008) determined engineering properties of garlic to design specific crop production and processing equipments like planting, handling, storing, aeration, drying, bulb breaking, peeling of garlic. Masoumi et al. (2006) also studied physical attributes of garlic for development of new methods of sowing, new equipment for processing and control strategies for crop storage.

Although the physical and biometric properties of the onion seedlings affects the design parameters of the transplanter, no detail .information is available on engineering properties of onion seedlings relevant to design of onion seedling transplanter. The aim of this study was to determine engineering properties of onion seedlings which could be useful for designing onion seedling transplanter. The study will provide information on average physical and mechanical properties of onion seedlings useful for selection and designing different components of onion seedling transplanting machine.

\section{MATERIALS AND METHODS}

Studies were conducted on three onion varieties; Pusa ridhi and Set- 126 (Kharif variety) and Pusa red (Rabi grown) commonly cultivated in India. Fresh onion (Allium cepa L.) seedlings were procured from experimental farm of Division of Vegetable Science IARI, New Delhi and also grown at the experimental farm of Division of Agricultural Engineering, IARI, New Delhi with the standard agronomic practice of nursery raising under the direction of onion breeder scientist. The seedlings were raised in the nursery in accordance with the recommended seed rate and cultural practices. As per the recommendations of the onion breeder, the onion seedlings are transplanted at 50 to 70 days according to climatic conditions of onion growing regions of the country. Therefore, biometric properties for design of onion seedling transplanter were considered at 50, 60 and 70 days after sowing. The studies on different biometric properties of twenty randomly selected samples of all three varieties at 50, 60 and 70 days of onion seedlings were conducted in laboratory of Division of Agricultural Engineering. The following engineering properties were studied.

Weight of seedlings: Onion seedlings are generally de -topped at 10-12 cm height before manual transplanting. Thus, twenty randomly selected seedlings were weighed without de-topping and with $10 \mathrm{~cm}$ de-topped height with the help of electronic weighing balance with least count of $0.001 \mathrm{~g}$. The weight of seedling is an important parameter because onion seedlings are lighter than other vegetable seedlings. The ease with which seedlings flows in different components of the machine is affected by the weight of seedlings. Because of gravitational effect, the heavier seedlings drops better than lighter seedlings.

Moisture content: The moisture content of onion seedlings was determined at transplanting stage. The standard method given by Association of Official Agricultural Chemists (AOAC) to determine the moisture content of seedlings was used for the purpose. The onion seedlings were cut in 3-4 thin slices, weighed and oven dried to constant weight at $60 \pm 2^{\circ} \mathrm{C}$ (AOAC, 2012; Stroshine, 1998).

Bulb and stem diameter of onion seedlings: The bulb and stem diameters of onion seedlings were measured at the centre of bulb and stem using vernier caliper with least count of $0.1 \mathrm{~mm}$ as suggested by Mohsenin (1986). These dimensions helps in determining minute details of metering mechanism like deciding the diameter of plugs in plug type mechanism, size of finger groove in finger planting mechanism.

Height of seedlings: The height of seedlings was measured through longest dimension with the help of steel tape as suggested by Mohsenin (1986). It helps to determine the length of plugs and fingers, length of funnel, diameter of press wheels, also need of detopping before transplanting by machine. As onion seedlings grows up to $30-40 \mathrm{~cm}$ in height, if planted without de-topping suitably, this may interfere in the movement of seedlings during mechanical transplanting as plant to plant distance is $10-12 \mathrm{~cm}$

Compressive strength: The compressive strength of the bulb and stem of onion seedlings were measured with the help of texture analyzer. The seedlings were compressed up to $30 \%$ of bulb and stem thickness respectively to assess compressive force to hold the seedlings with minimum damage. The compression distance was selected as $30 \%$ of total thickness as it gave minimum damage and mortality as well as optimum gripping force. Compressive force gives an idea about the magnitude of compressive force which seedlings can bear at different stages of transplanting operation. Following settings of texture analyzer was used during the experimentation for compressive force measurement.

Coefficient of static friction: The angle of friction of onion seedlings on commonly used materials in fabrication such as mild steel, aluminum and galvanized iron surfaces was measured by using a calibrated tilting table (Varshney et al., 2005). The seedling was kept on horizontal plane sheets of these materials and 


\section{Particulars}

Load cell capacity

Pre-test speed

Test speed

Post- test speed

Compression Distance

Probe

\author{
Specification \\ $25 \mathrm{~kg}$ \\ $5 \mathrm{~mm} / \mathrm{sec}$ \\ $0.5 \mathrm{~mm} / \mathrm{sec}$ \\ $10 \mathrm{~mm} / \mathrm{sec}$ \\ $30 \%$ \\ $1 / 2$ " cylindrical ebonite
}

inclination was gradually raised. The angle at impending slip was recorded. The coefficient of static friction was tangent of the angle measured. The coefficient of static friction was computed using the following formula:

\section{$\mu=\tan \delta$}

Where,

$\mu=$ Coefficient of friction, and

$\delta=$ Angle at impending slip, degree.

\section{RESULTS AND DISCUSSION}

Weight of seedlings: The weight of onion seedlings without and with de-topping is given in table 1 . The average weight of onion seedlings without de-topping was $0.57,2.49$ and $3.05 \mathrm{~g}$ (Pusa Red); 0.61, 1.21 and $1.37 \mathrm{~g}$ (Set 126); 0.53, 1.07 and 1.35g (Pusa Ridhi) and with de-topping at $10 \mathrm{~cm}$ seedling height was 0.47 ,

1.35 and $1.68 \mathrm{~g}$ (Pusa Red); 0.54, 0.98 and 1.12g (Set 126); 0.49, 0.86, $1.05 \mathrm{~g}$ (Pusa Ridhi) for 50, 60 and 70 days old seedlings, respectively. The 50 days old seedlings were thin and very light in weight whereas 60 and 70 days seedlings were heavy. The weight of onion seedlings increased with the age. The varieties Set-126 and Pusa Ridhi were lighter due to their poor growth as compared to Pusa Red. The poor growth of Set-126 and Pusa Ridhi was due to unfavorable growing conditions in the kharif season than in the rabi season. The weight of seedlings is in direct relationship with height (Fig. 1).

Bulb and stem diaeter: The diameter of bulbs and stems of onion seedling are given in table 1 . The average diameter of bulbs were 3.13, 4.88 and 5.76 $\mathrm{mm}$ (Pusa Red); 4.07, 4.86 and $5.35 \mathrm{~mm}$ (Set 126); $4.31,4.74$ and $5.48 \mathrm{~mm}$ (Pusa Ridhi) and for stems 2.44, 3.78 and $4.33 \mathrm{~mm}$ (Pusa Red); 2.96, 3.30 and $3.54 \mathrm{~mm}$ (Set 126); 2.73, 3.45, $3.59 \mathrm{~mm}$ (Pusa Ridhi) for 50,60 and 70 days old seedlings, respectively. These results show that diameter of onion seedling bulbs increases with increase in age of seedlings. The holding mechanism of seedling transplanter can be designed on the basis of observed dimension.

Height of onion seedlings: Height of onion seedlings

Table 1. Biometric properties of twenty onion seedlings of each variety at different age.

\begin{tabular}{lccccc}
\hline $\begin{array}{l}\text { Age } \\
\text { seedlings (Days) }\end{array}$ & $\begin{array}{c}\text { Weight without } \\
\text { detopping (g) }\end{array}$ & $\begin{array}{c}\text { Weight with } \\
\text { detopping (g) }\end{array}$ & $\begin{array}{c}\text { Bulb diameter } \\
(\mathbf{m m})\end{array}$ & $\begin{array}{c}\text { Stem diameter } \\
(\mathbf{m m})\end{array}$ & $\begin{array}{c}\text { Height } \\
(\mathbf{c m})\end{array}$ \\
\hline Pusa Red & & & & & $17.65 \pm 1.35$ \\
\hline 50 & $0.57 \pm 0.16$ & $0.47 \pm 0.13$ & $3.13 \pm 0.4$ & $2.44 \pm 0.38$ & $32.04 \pm 3.17$ \\
60 & $2.49 \pm 0.46$ & $1.35 \pm 0.19$ & $4.88 \pm 0.4$ & $3.78 \pm 0.37$ & $34.65 \pm 3.88$ \\
\hline 70 & $3.05 \pm 0.55$ & $1.68 \pm 0.29$ & $5.76 \pm 0.56$ & $4.33 \pm 0.41$ & \\
\hline Set - 126 & & & & & $15.27 \pm 2.09$ \\
\hline 50 & $0.61 \pm 0.20$ & $0.54 \pm 0.15$ & $4.07 \pm 0.62$ & $2.96 \pm 0.57$ & $19.64 \pm 4.51$ \\
60 & $1.21 \pm 0.27$ & $0.98 \pm 0.11$ & $4.86 \pm 0.49$ & $3.30 \pm 0.34$ & $21.58 \pm 3.07$ \\
\hline Pusa Ridhi & $1.37 \pm 0.21$ & $1.12 \pm 0.11$ & $5.35 \pm 0.69$ & $3.54 \pm 0.31$ & \\
\hline 50 & & & & & \\
60 & $0.53 \pm 0.19$ & $0.49 \pm 0.16$ & $4.31 \pm 0.21$ & $2.73 \pm 0.61$ & $14.48 \pm 2.16$ \\
70 & $1.07 \pm 0.20$ & $0.86 \pm 0.21$ & $4.74 \pm 1.15$ & $3.45 \pm 0.38$ & $18.27 \pm 2.06$ \\
\hline
\end{tabular}

Table 2. Compressive strength, distance and time of 50,60 and 70 days for twenty onion seedlings of each variety at different age.

\begin{tabular}{|c|c|c|c|c|c|c|}
\hline \multirow{2}{*}{$\begin{array}{l}\text { Age of seed- } \\
\text { lings (Days) }\end{array}$} & \multicolumn{3}{|c|}{ Bulb } & \multicolumn{3}{|c|}{ Stem } \\
\hline & Force $(\mathrm{N})$ & Distance (mm) & Time (s) & Force $(\mathbf{N})$ & Distance (mm) & Time (s) \\
\hline \multicolumn{7}{|l|}{ Pusa Red } \\
\hline 50 & $10.65 \pm 1.61$ & $0.92 \pm 0.14$ & $1.85 \pm 0.27$ & $4.38 \pm 0.87$ & $0.72 \pm 0.10$ & $1.46 \pm 0.19$ \\
\hline 60 & $15.93 \pm 2.17$ & $1.56 \pm 0.16$ & $3.13 \pm 0.32$ & $6.75 \pm 1.54$ & $1.29 \pm 0.14$ & $2.59 \pm 0.28$ \\
\hline 70 & $18.53 \pm 3.47$ & $1.71 \pm 0.19$ & $3.43 \pm 0.38$ & $7.80 \pm 1.45$ & $1.33 \pm 0.12$ & $2.66 \pm 0.47$ \\
\hline \multicolumn{7}{|l|}{ Set -126} \\
\hline 50 & $10.88 \pm 1.46$ & $1.04 \pm 0.15$ & $2.07 \pm 0.30$ & $4.93 \pm 0.63$ & $0.86 \pm 0.12$ & $1.71 \pm 0.24$ \\
\hline 60 & $15.24 \pm 2.18$ & $1.37 \pm 0.22$ & $2.75 \pm 0.43$ & $7.10 \pm 1.13$ & $1.21 \pm 0.07$ & $2.41 \pm 0.15$ \\
\hline 70 & $19.54 \pm 2.09$ & $1.51 \pm 0.33$ & $3.03 \pm 0.65$ & $8.17 \pm 1.54$ & $1.43 \pm 0.13$ & $2.86 \pm 0.27$ \\
\hline \multicolumn{7}{|l|}{ Pusa Ridhi } \\
\hline 50 & $9.76 \pm 1.57$ & $0.94 \pm 0.38$ & $1.89 \pm 0.76$ & $4.08 \pm 0.75$ & $0.79 \pm 0.08$ & $1.59 \pm 0.16$ \\
\hline 60 & $14.77 \pm 1.26$ & $1.43 \pm 0.22$ & $2.87 \pm 0.43$ & $6.28 \pm 0.61$ & $1.17 \pm 0.16$ & $2.35 \pm 0.33$ \\
\hline 70 & $18.69 \pm 1.43$ & $1.64 \pm 0.23$ & $3.13 \pm 0.49$ & $7.98 \pm 1.21$ & $1.37 \pm 0.14$ & $2.75 \pm 0.28$ \\
\hline
\end{tabular}


Table 3. Moisture content and Coefficient of static friction of twenty onion seedlings of each variety at different age.

\begin{tabular}{lccccc}
\hline Parameters & Variety & & Pusa Red & Pusa Ridhi & Set-126 \\
\hline \multirow{2}{*}{ Moisture content (wb \%) } & & 50 & 91.63 & 88.11 & 89.79 \\
& Age (Days) & 60 & 88.83 & 84.89 & 90.09 \\
& & 70 & 87.07 & 85.80 & 86.82 \\
Coefficient of Static friction & Materials & & GI & MS & Al \\
(Set-126) & Age (Days) & 50 & 0.79 & 0.78 & 0.69 \\
& & 70 & 0.73 & 0.7 & 0.7 \\
\hline
\end{tabular}

GI- Galvanized iron; MS - Mild Steel; Al - Aluminum.

are shown in table 1 . The average height of onion seedlings at the age of 50, 60 and 70 days were observed as 17.65, 32.04 and $34.65 \mathrm{~cm}$ (Pusa Red) ; $15.27,19.64$ and $21.58 \mathrm{~cm}$ (Set 126); 14.48, 18.27 and $19.45 \mathrm{~cm}$ (Pusa Ridhi), respectively. These heights of onion seedlings were too large to be handled with metering mechanism of a transplanter. Prior to transplanting operation, the top shoots of the seedlings needs to be cut which enhance the fast development of shoots and also for easy handling and transplanting through metering mechanism. The uniform height obtained after de-topping will enhance the machine performance.

Compressive strength of bulb and stem: The compressive strength $(\mathrm{N})$ of onion seedlings are shown in table 2 and fig 2 . The average compressive strength of onion seedlings at the age of 50,60 and 70 days were found to be 10.65, 15.93 and $18.53 \mathrm{~N}$ (Pusa Red); 10.88, 15.24 and 19.54 N (Set 126); 9.76, 14.77, 18.69 N (Pusa Ridhi) for bulb and 4.38, 6.75 and 7.8 N (Pusa Red); 4.93, 7.10 and 8.17 N (Set 126); 4.08, 6.28, 7.98 (Pusa Ridhi) for stem, respectively. The data shows that the compressive strength of onion seedlings increased with increase in age of seedlings. The 60 and 70 days seedlings have higher compressive strength hence they are more suitable for transplanter while handling and transportation, uprooting from nursery, holding and dropping in the machine and also for soil covering and compaction with press wheels. Bahnasawy et al. (2004) an increase in crushing load with the increase in bulb size. For small, medium and large sizes, the average crushing load increased from 443.3

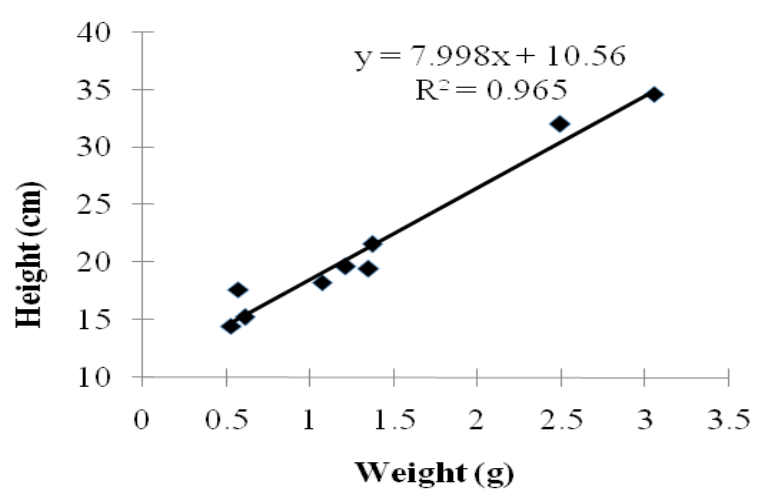

Fig. 1. Relationship between height and weight of onion seedling. to $819.7 \mathrm{~N}, 341.4$ to $980.7 \mathrm{~N}$ and 400 to $780 \mathrm{~N}$ for the white, red and yellow onion, respectively. Vijaya and Srivastava (2006) also observed an increase in the cutting force with increased neck diameter for NP53, Pusa Red and Agrifound Dark varieties, respectively. The cutting force data could be used to design the blades of onion de-topping machine for cutting the neck of the onion.

Khura et al. (2010) found that the mean value of maximum crushing force required for the onion bulb increased by $30 \%$ with change in size from small to medium and $25 \%$ from medium to large size bulbs. The average time for which compression can be sustain without unbearable damage increased with diameter, the highest compression time achieved was 3.43 and $2.86 \mathrm{~s}$ for bulbs and stems of 70 days seedlings respectively (Fig.2). It means older seedlings can be handled for longer period of time. All seedlings were compressed for $30 \%$ of initial dimension and latter transplanted manually in field to observe its mortality which was observed as zero mortality within three days after transplanting.

Moisture content of seedlings: The moisture content (wb \%) of seedlings at all three stages of transplanting and for three onion varieties are shown in table 3 . The moisture content for all three varieties varied from $91.63 \%$ (Pusa Red) to $84.89 \%$ (Pusa Ridhi). The result shows that there is slight reduction in moisture content of seedlings with age. This is due to the fact that, as the seedlings gets mature there is subsequent reduction in watering to allow their hardening. Bahnasawy et al. (2004) found 81.3, 80.9 and $79.7 \%$ (w.b.) moisture content for bulbs of Giza 6 (white), Beheri (red) and Giza 20 (yellow onion), respectively. The moisture content of bulbs were lower as compared to transplanting stage due to the reduction of irrigation before start of harvesting.

Coefficient of static friction: The mean coefficient of static friction was $0.79,0.73$ and 0.7 for (GI); 0.78, 0.7 and 0.68 for (MS); and $0.69,0.7$ and 0.63 for $(\mathrm{Al})$ respectively for 50, 60 and 70 days seedlings (Table 3 ). The 50 days old onion seedlings had higher coefficient of static friction as compared to 60 and 70 days old seedlings. The coefficient of static friction had the inverse relationship with age of seedlings. This may be due to reason that the 50 days seedlings are lighter in weight and smaller in size than 60 and 70 

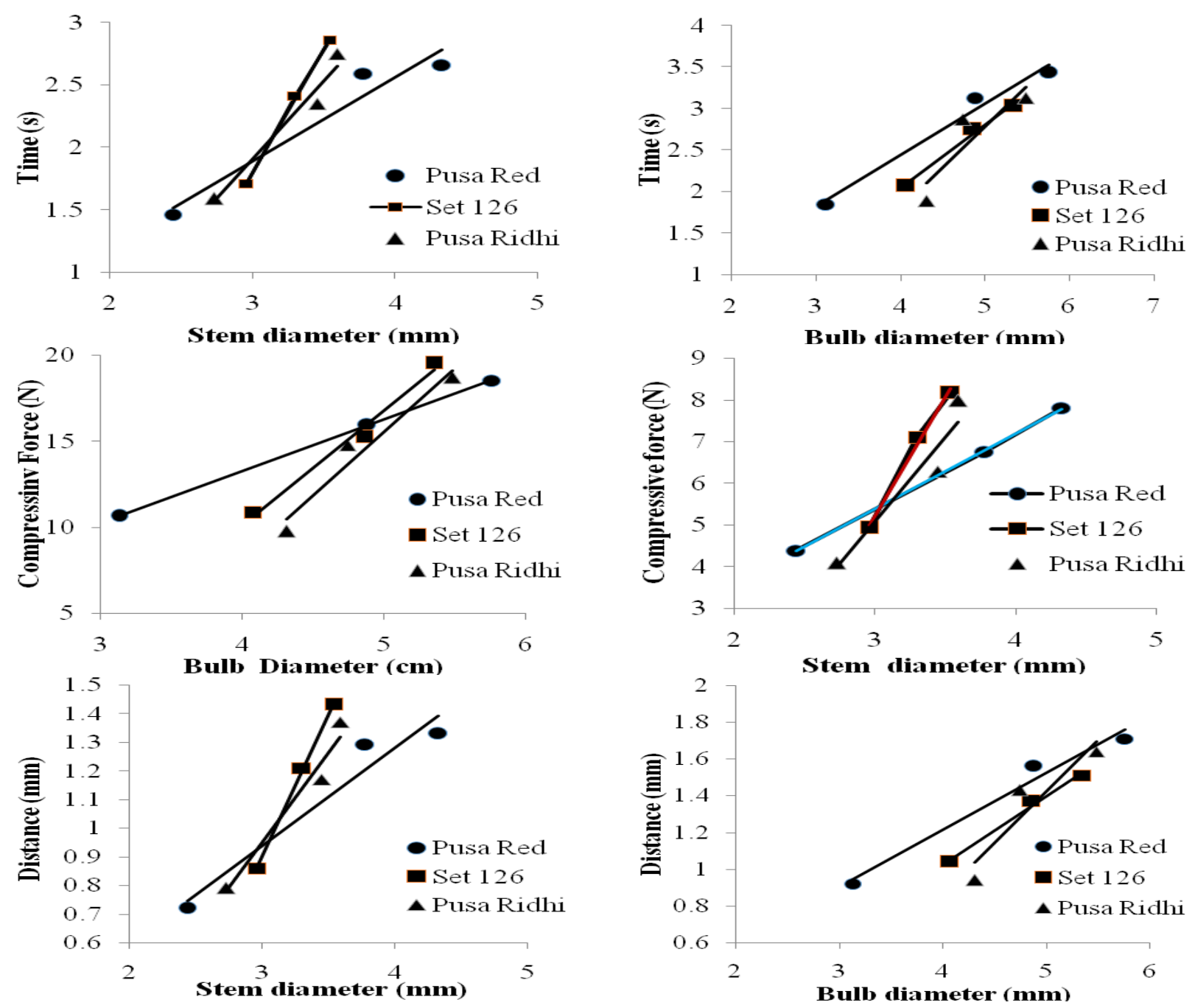

Fig. 2. Effect of bulb and stem diameter on compressive force, compression distance and time of compression of bulb and stem.

days seedlings. The shorter leaves of the young seedlings do not allow the bulb to get displaced from the respective position and thus slides down only when the angle of static friction increased. In case of older seedlings, their higher weight can support the length of leaves and are not much affected by the length of the leaves and roll down at lower angle of static friction. Khura et al. (2010) reported coefficient of static friction values as $0.42,0.38$ and 0.35 for onion bulbs on mild steel surface for small, medium and large size of bulb, respectively i.e. it decreased with increase in diameter of onion bulb. Vijaya Rani and Srivastava (2006) also found higher coefficient of static friction for lower equatorial diameter onions. The mean coefficient of static friction was $0.43,0.41$ and 0.41 respectively which were inversely related to mean equatorial diameters of $39.81,58.41$ and $53.46 \mathrm{~mm}$ for the three onion varieties. Haciseferogullari et al. (2005) obtained $0.416,0.472$ and 0.541 values of static coefficient of friction for garlic segment at $66.32 \%$ (d.b.) moisture content on galvanized steel, an iron sheet and a plywood surface, respectively.

\section{Conclusion}

The weight of onion seedlings without de-topping ranged from 0.53 to $3.05 \mathrm{~g}$ while with de-topping at 10 $\mathrm{cm}$ ranged from 0.47 to $1.68 \mathrm{~g}$ for all the three cultivars. The bulb and stem diameter for all varieties ranged from 3.13 to $5.76 \mathrm{~g}$ for bulb and 2.44 to $4.33 \mathrm{~g}$ for stem whereas height varied from $14.48 \mathrm{~cm}$ to 34.65 $\mathrm{cm}$, among all Pusa red was taller than Set-126 and Pusa Ridhi. The diameter, weight, height of onion seedlings increased with age making them hardy, which is desirable for designing/selection of transplanter components. These biometric properties will also be useful for different adjustments in transplanter. The values of diameter of bulb and stem and height of seedlings would be useful in deciding the diameter and length of plugs in plug and size of fingers in finger type mechanism. The moisture content at different age and cultivars ranged from 84.89 to 91.63 $\%$ (wb). The average coefficient of static friction for mild steel, aluminum and GI varied from 0.63 to 0.79 . The compressive strength of bulb and stem of seedlings were 9.76 to $19.54 \mathrm{~N}$ for bulb and 4.08 to 
$8.17 \mathrm{~N}$ for stem, respectively for 50 to 70 days seedlings. The compressive strength values of seedlings would be useful in deciding optimum holding force, maximum handling time of seedlings without damage. This information is critical in designing different components of onion seedling transplanter.

\section{REFERENCES}

APEDA (2015). Agricultural and Processed Food Products Export Development Authority Government of India. Retrieved July 17, 2015. From http://agriexchange. apeda.gov.in/indexp/Product_description_32head.aspx? gcode $=0201$

AOAC (2012). Official Methods of Analysis, Association of Official Agricultural Chemists, $19^{\text {th }}$ Edn-Washington, D.C.

Bahnasawy, A. H.(2007). Some physical and mechanical properties of garlic. Int. J. Food Engg. 3(6) : 1-18

Bahnasawy, A. H., El-Haddad, Z. A., El-Ansary, M. Y. and Sorour, H.M. (2004). Physical and mechanical properties of some Egyptian onion cultivars. J. Food Engg., $62: 255-261$

Csizmazia, Z and Polyak, N. I. (1994). The determination of physical characteristics of seeds for the construction of seeding machines. The proceedings of the ninth, international conference and exhibition on mechanization of field experiments, Beijing, China, 90-97.

Haciseferogullari, H., Ozcan, M., Demir, F. and Calisir S. (2005). Some nutritional and technological properties of garlic. J. Food Engg., 68: 463-469.
Khura, T. K., Indra Mani and Srivastava, A.P. (2010). Some engineering properties of onion crop relevant to design of onion digger. J. Agric. Engg., 47 (1) : 1-8

Manjunatha, M., Samuel, D. V. K. and Jha, S.K. (2008). Some engineering properties of garlic (Alliumsativum L). J. Agril. Engg., 45 (2): 18-23.

Masoumi, A. A., Rajabipoor, A., Tabil, L. G. and Akram, A. A. (2006). Physical attributes of garlic (allium sativum 1.). J. Agric. Sci. Technol., 8: 15-23.

Mohsenin, N. N. (1986). Physical properties of plant and animal material. Gordon and Breach, New York.

NHRDF (2014). NHRDF- RESEARCH (1978-2013). Technical Bulletin No. 16. Nashik (MS), India, National Horticultural Research and Development Foundation. Retrieved September 12, 2014. From http://nhrdf.com/ documents/NHRDF-Research-Achievements.pdf

Sampath Kumar, K. P., Bhowmik, D., Chiranjib, Biswajit and Tiwari, P. (2010). Allium cepa: a traditional medicinal herb and its health benefits. J. Chem. Pharma. Res., 2(1): 283-291.

Stroshine, R. (1998). Physical properties of agricultural materials and food products. Department of agricultural and biological engineering. Purdue university. West Lafayette, Indiana.

Vashaney, A. K., Vyas, D. M. and Akbari, S. H. (2005). Some physical and engineering properties of cumin seed. Agric. Engg. Today. 28 (3-4): 7-10.

Vijaya Rani and Srivastava, A. R. (2006). Physical and mechanical properties of onion (Allium Cepa L.) crop relevant to mechanical detopping. J. Agric. Engg., 43 (3): 83-86. 